\title{
Correction to: Agrobacterium: A Genome-Editing Tool-Delivery System
}

Nagesh Sardesai and Subhashree Subramanyam

\section{Correction to:}

Chapter "Agrobacterium: A Genome-Editing Tool-Delivery

System" in: N. Sardesai and

S. Subramanyam, Current Topics in Microbiology

and Immunology, https://doi.org/10.1007/82_2018_136

By mistake the chapter was published with incorrect author name. The chapter has now been corrected.

The updated online version of this chapter can be found at https://doi.org/10.1007/82_2018_101

N. Sardesai $(\bowtie)$

Corteva Agriscience ${ }^{\mathrm{TM}}$, Agriculture Division of DowDuPont,

8305 NW 62nd Avenue, Johnston, IA, USA

e-mail: nsardesai@dow.com

\section{S. Subramanyam}

Department of Agronomy, Purdue University, 915 W State Street,

West Lafayette, IN 47907, USA

e-mail: shubha@purdue.edu

Current Topics in Microbiology and Immunology (2018) 418:E1

DOI 10.1007/82_2018_136

(C) Springer Nature Switzerland AG 2018

Published Online: 20 September 2018 